\title{
To asses the practices and attitude regarding iron deficiency anemia in adolescence girls of Amreli
}

\author{
Neha Tiwari, Jiju N. Vyas and N. S. Joshi
}

The study was conducted in purposively selected Amreli city of Gujarat State. Five Higher Secondary School were purposively selected from Amreli city i.e., Municipal Girls High School, Ji Ji Ben Forward High School, Smt. S.S. Ajmera School, Smt. Shantaben Haribhai Gajera Sankul and B.N. Virani Higher School having maximum number of adolescence who were willing to participate in this study and were available during the period of data collection. Out of five higher secondary school 30 adolescences girls were randomly selected constituting the total sample of 150 adolescences girls for the present study. Data were collected with the help of structured interview schedule. Frequencies, Percentage and mean per cent score were used for analyzing the data statistically. out that 56.6 per cent of the respondents were from medium socio- economic status whereas 43.3 per cent of the respondents were in low socio-economic status. None of the respondents had high socio-economic status. Nearly half of the respondents (46.7 \%) taking IFA(Iron folic acid), 73.3 per cent of the respondents know its benefits and none of the respondents feel any side effect after taking IFA tablets. More than half of the respondents $(57.3 \%)$ feel weakness, $(50.0 \%)$ feel easily tired, feel breathless (13.3\%) while doing routing work due to the deficiency of iron. Most of the respondents (70.0 MPS) feel fatigue, dizziness and leg cramps. Majority of the respondents $(80.0 \%)$ know that diet make a difference in anemia prevention, inclusion of iron-rich food in daily diet $(80.0 \%)$ and green leafy veg nutrition helps in improving iron level $(80.0 \%)$, with mean per cent score 70.0.

Key Words : Practices, Attitude regarding iron, Deficiency anemia, Adolescence girls

How to cite this article : Tiwari, Neha, Vyas, Jiju N. and Joshi, N.S. (2020). To asses the practices and attitude regarding iron deficiency anemia in adolescence girls of Amreli. Food Sci. Res. J., 11(2): 189-194, DOI : 10.15740/HAS/FSRJ/11.2/189-194.Copyright@, 2020: Hind Agri-Horticultural Society.

Author for correspondence :

Neha Tiwari, Krishi Vigyan Kendra (JAU) Amreli (Gujarat) India

Email: nehatiwari@jau.in

Associate Authors' :

Jiju N. Vyas, Sardarkrushinagar Dantiwada Agricultural University,

Dantiwada (Gujarat) India

N.S. Joshi, Krishi Vigyan Kendra $(\overline{J A U})$ Amreli (Gujarat) India 